\title{
Short-term effect of the New Nordic Renal Diet on phosphorus homoeostasis in chronic kidney disease Stages 3 and 4
}

Salomo, Louise; Rix, Marianne; Kamper, Anne-Lise; Thomassen, Jesper Q; Sloth, Jens Jørgen; Astrup, Arne

Published in:

Nephrology, Dialysis, Transplantation

Link to article, DOI:

10.1093/ndt/gfy366

Publication date:

2019

Document Version

Publisher's PDF, also known as Version of record

Link back to DTU Orbit

Citation (APA):

Salomo, L., Rix, M., Kamper, A-L., Thomassen, J. Q., Sloth, J. J., \& Astrup, A. (2019). Short-term effect of the New Nordic Renal Diet on phosphorus homoeostasis in chronic kidney disease Stages 3 and 4. Nephrology, Dialysis, Transplantation, 34(10), 1691-1699. [gfy366]. https://doi.org/10.1093/ndt/gfy366

\section{General rights}

Copyright and moral rights for the publications made accessible in the public portal are retained by the authors and/or other copyright owners and it is a condition of accessing publications that users recognise and abide by the legal requirements associated with these rights.

- Users may download and print one copy of any publication from the public portal for the purpose of private study or research.

- You may not further distribute the material or use it for any profit-making activity or commercial gain

- You may freely distribute the URL identifying the publication in the public portal 


\title{
Short-term effect of the New Nordic Renal Diet on phosphorus homoeostasis in chronic kidney disease Stages 3 and 4
}

\author{
Louise Salomo ${ }^{1,2}$, Marianne Rix ${ }^{1}$, Anne-Lise Kamper ${ }^{1}$, Jesper Q. Thomassen ${ }^{3}$, Jens J. Sloth ${ }^{4}$ and \\ Arne Astrup ${ }^{2}$ \\ ${ }^{1}$ Department of Nephrology, University Hospital of Copenhagen, Rigshospitalet, Denmark, ${ }^{2}$ Department of Nutrition, Exercise and Sports, \\ Faculty of Science, University of Copenhagen, Denmark, ${ }^{3}$ Department of Clinical Biochemistry, University Hospital of Copenhagen, \\ Rigshospitalet, Denmark and ${ }^{4}$ National Food Institute, Technical University of Denmark, Kemitorvet, Denmark
}

Correspondence and offprint requests to: Louise Salomo; E-mail: louise.havkrog.salomo@regionh.dk

\section{ABSTRACT}

Background. The New Nordic Diet is a food concept favouring organically produced food items, fruits, vegetables, whole grains and fish. We investigated the short-term effects of a modified phosphorus-reduced New Nordic Renal Diet (NNRD) in chronic kidney disease (CKD) patients on important parameters of phosphorus homoeostasis.

Methods. The NNRD contained a total of $850 \mathrm{mg}$ phosphorus/ day. A total of 18 patients, CKD Stages 3 and 4 were studied in a randomized crossover trial comparing a 1-week control period of the habitual diet with a 1-week period of the NNRD. Data were obtained at baseline and during 1 week of dietary intervention (habitual diet versus NNRD) by collecting fasting blood samples and 24-h urine collections. The primary outcome was the difference in the change in 24-h urine phosphorus excretion from baseline to Day 7 between the NNRD and habitual diet periods. Secondary outcomes were changes in the fractional excretion of phosphorus, fibroblast growth factor 23 (FGF23) and plasma phosphate.

Results. As compared with the habitual diet, 24-h urine phosphorus excretion was reduced in the NNRD by $313 \mathrm{mg} /$ day $(\mathrm{P}<0.001)$. The mean baseline phosphorus was $875 \pm 346 \mathrm{mg} /$ day and was decreased by $400 \pm 256 \mathrm{mg} /$ day in the NNRD and $87 \pm 266 \mathrm{mg} /$ day in the habitual diet. The $24-\mathrm{h}$ urine fractional excretion of phosphorus decreased by $11 \%(\mathrm{P}<0.001)$ and FGF23 decreased by $30 \mathrm{pg} / \mathrm{mL}(\mathrm{P}=0.03)$ with the NNRD compared with the habitual diet. Plasma phosphate did not change.

Conclusion. This study demonstrates that dietary phosphorus restriction in the context of the NNRD is feasible and has positive effects on phosphorus homeostasis in CKD patients.

Keywords: 24-h urine phosphorus excretion, chronic kidney disease (CKD), dietary intervention, fibroblast growth factor 23 (FGF23), New Nordic Renal Diet (NNRD)

\section{INTRODUCTION}

Chronic kidney disease (CKD) causes severe disturbances in phosphate metabolism, and observational studies link hyperphosphataemia and elevated levels of fibroblast growth factor 23 (FGF23) to the increased cardiovascular morbidity and mortality in CKD [1-6].

There is an unmet need to develop safe and sustainable therapeutic approaches to lower phosphate and FGF23 levels in CKD to prevent the vascular calcifications and left ventricular hypertrophy found in the majority of end-stage renal disease patients [7].

Dietary phosphorus exposure and absorption are modifiable factors; however, studies of dietary interventions to reduce phosphorus load and FGF23 in patients with moderate CKD have shown conflicting results. Some demonstrated a positive effect, especially on FGF23 $[8,9]$, whereas others have failed to show any influence [10-12].

Changing the eating habits of a population on a long-term basis presents a major challenge [13], but with the typically high phosphorus content of the Western diet due to considerable amounts of meat-based protein and phosphorus-containing food additives, this would be necessary $[14,15]$.

Beneficial effects of healthy eating habits regarding cardiovascular morbidity and mortality have been demonstrated by the two widely recommended food-based dietary patterns, namely the Mediterranean diet [16] and the Dietary Approaches to Stop Hypertension (DASH) diet [17, 18]. Both of these diets may also have potential beneficial effects on the progression of CKD [19-21].

A recent Danish initiative to develop palatable, healthy and sustainable dietary recommendations based on foods produced in the Nordic region, called the New Nordic Diet (NND), has been tested in different population groups, with promising results regarding cardiovascular risk profile [22]. The diet is 
Table 1. Diet composition of the NNRD and control diet on Day 7

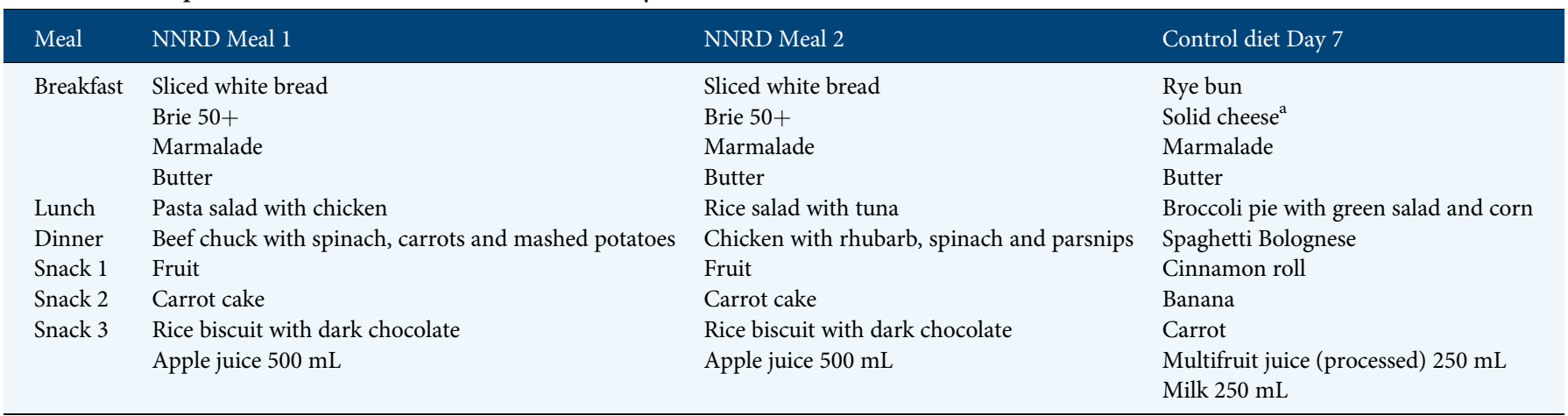

During the NNRD, water, coffee and tea were ad libitum (no milk). No alcohol was allowed.

${ }^{\text {a}}$ Phosphorus-containing food additives.

very similar to the Mediterranean diet, but with replacement of, for example, olive oil with rapeseed oil, garlic with rams, etc. We have previously tested the phosphorus content of the NND and did not find it suitable for the CKD population in its present form [23].

Modification of the NND into the New Nordic Renal Diet (NNRD) to suit the needs and preferences of the Danish CKD Stages 3 and 4 population was developed. This new concept is introduced and tested in the present study.

\section{MATERIALS AND METHODS}

\section{Study protocol}

The study was registered at www.clinicaltrials.gov as NCT03052582 and was conducted according to the Helsinki Declaration, and all patients signed an informed consent form after receiving oral and written information.

\section{Subjects}

A total of 19 patients were recruited from the outpatient clinic at the Department of Nephrology, Rigshospitalet and 1 patient from Herlev Hospital. The study was carried out between February and November 2017. Patients fulfilled the following criteria: age between 18 and 82 years, estimated glomerular filtration rate (eGFR) $16-45 \mathrm{~mL} / \mathrm{min} / 1.73 \mathrm{~m}^{2}$, as judged by the Chronic Kidney Disease Epidemiology Collaboration equation, medically stable for 2 months before and during the study, no food allergies and the ability to understand the Danish language orally and in writing. Patients taking phosphate binders were excluded from participating.

\section{Development of the NNRD}

The NND [24] has been tested in different populations, with promising results regarding the cardiovascular risk profile, and the Nordic diet has been recognized by World Health Organization to represent a healthy alternative to the Mediterranean diet [25]. We investigated whether the NND could serve as a recommended diet in $\mathrm{CKD}$ patients by estimating the phosphorus content and absorption of the NND; however, this was not the case in its present form [23]. We modified
Table 2. Diet content of the NNRD and control diet on Day 7

\begin{tabular}{lccc}
\hline Diet content & NNRD & NNRD & Control \\
& Meal 1 & Meal 2 & diet \\
\hline Energy (kcal) & 2427 & 2428 & 2431 \\
Total fat/carbohydrate/protein (\%) & $34 / 54 / 12$ & $35 / 54 / 11$ & $34 / 51 / 15$ \\
Total fat/carbohydrate/protein (g) & $91 / 308 / 68$ & $97 / 300 / 65$ & $91 / 287 / 93$ \\
Protein (g/kg/day) & 0.84 & 0.8 & 1.15 \\
Phosphorus (mg) & 862 & 817 & 1579 \\
Total fibre (g) & 27 & 26 & 23 \\
Calcium (mg) & 816 & 851 & 1205 \\
Sodium (g/day) & 2.90 & 3.03 & 3.30 \\
Potassium (g/day) & 2.81 & 2.40 & 3.50 \\
\hline
\end{tabular}

the NND into the NNRD by removing the most phosphorusrich food items, such as rye bread, dairy products, nuts and fish but still keeping in mind a nutritiously well-balanced diet with a phosphorus content of $\sim 850 \mathrm{mg} /$ day (Tables 1 and 2).

\section{Study design}

This was a randomized controlled crossover study of two diets in patients with CKD Stages 3 and 4 (Figure 1). Baseline data (Day 0) were obtained, including 24-h urine collection, fasting blood samples and dietary record. During the intervention, the participants received the NNRD for 1 week and fasting blood samples and 24-h urine collection were collected on Days 1 and 4. During the control period, the participants kept to their habitual diet from Days 1 to 6 (on Days 1 and 4 they kept a dietary record and collected 24-h urine samples) and on Day 7 they received a control diet with a phosphorus content in accordance with an average Danish diet (1500 mg). On Day 7, in both of the intervention periods, the patients were admitted to the Department of Nephrology, University Hospital of Copenhagen, Rigshospitalet, to follow the circadian rhythm of plasma phosphate, plasma intact FGF23, plasma ionized calcium and plasma parathyroid hormone (PTH). A fasting blood sample and 24-h urine collection were obtained and blood was additionally drawn $30 \mathrm{~min}$ after each of the three meals (see Figure 1).

The 24-h urine creatinine excretion was used as a requisite for the quality of the 24-h urine collection and it was without difference [26]. 

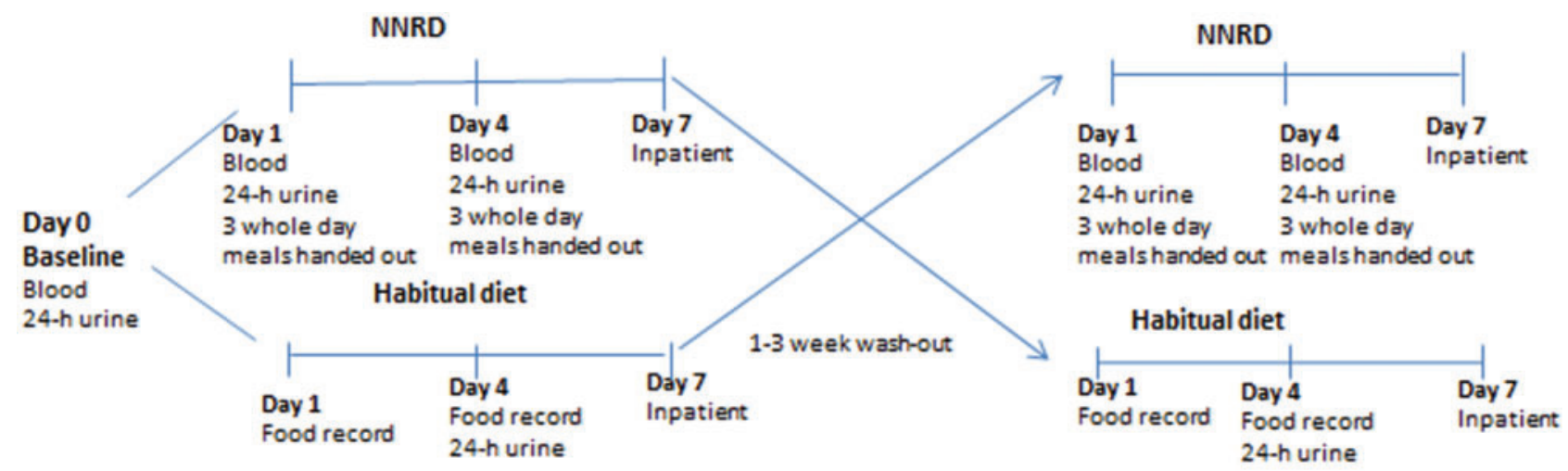

Inpatient

8 am

Fasting blood

24-h urine

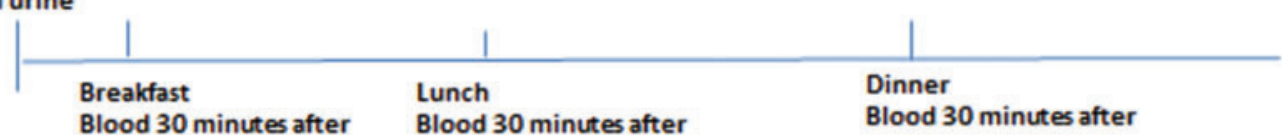

- NNRD, New Nordic Renal Diet

FIGURE 1: Overall study design. Top panel illustrates the crossover design and the lower panel demonstrates the blood samples taken during the inpatient stay.

\section{Study meals}

Diet planning was initially conducted using the Food Composition Databank (version 7.01, 2009, Copenhagen, Denmark). The diet during the intervention was designed to be iso-energetic, with a maximum total energy amount of $\sim 10000$ $\mathrm{kJ}$ (based on the average intake by a 50 - to 60 -year-old male with moderate physical activity). The phosphorus content in the meals was determined by inductively coupled plasma mass spectrometry at the National Food Institute, Technical University of Denmark, Kongens Lyngby, Denmark. The measured phosphorus content was approximately equal to the phosphorus content estimated by using the Food Composition Databank and the NNRD meals were consequently kept unchanged. No additional food was allowed during 7 days ingesting the NNRD and the food was handed out as packaged meals on Days 1 and 4 in the morning and consumed as outpatients.

Food was prepared by the metabolic kitchen of the Department of Nutrition, Exercise and Sports, Faculty of Science, University of Copenhagen, Copenhagen, Denmark.

\section{Self-reporting questionnaire}

Diet satisfaction, compliance and satiation were monitored by self-reporting intake in written study diaries, which were assessed at the end of the NNRD week. Dietary satisfaction was judged on a five-level Likert scale with following response options: very good, well, okay, not good and bad. A similar method was used for dietary compliance, with the following response options: $100,80,60,40$ and $20 \%$. The satiation was judged by yes or no.

\section{Laboratory analyses}

All samples for biochemical analysis were obtained from peripheral venous blood. The plasma and urine levels of creatinine and phosphorus were measured using standard laboratory methods on the Modular/Cobas Analyzer (Roche, Mannheim, Germany) at the Department of Clinical Biochemistry, Rigshospitalet. Plasma human intact FGF23 was measured by an FGF23 enzyme-linked immunosorbent assay kit (Kainos Laboratories, Tokyo, Japan) by batched analyses at the end of the study with an intra-assay coefficient of variation of $6 \%$ and interassay coefficient of variation of $10 \%$.

\section{Statistical analyses}

This study is based on a crossover design with a washout period between the two interventions, which reduces the betweensubject variability from the two diet periods. Measurements within each subject were correlated, as several measurements were made on each subject.

The change in 24-h urine phosphorus excretion was considered a strong proxy for reduced phosphorus absorption and therefore the primary outcome was the difference in the change in 24-h urine phosphorus excretion from baseline to Day 7 between the NNRD and habitual diet period of the study.

To be able to detect a minimum relevant difference of $200 \mathrm{mg}$ in the 24-h urine phosphorus excretion with a power of $80 \%$ and a two-sided alpha risk of $5 \%$ and a standard deviation (SD) of $200 \mathrm{mg}$, we estimated the sample size to be 18 patients.

Secondary outcomes were changes in the 24 -h urine fractional excretion of phosphorus, plasma intact FGF23, plasma phosphate, 24-h urine excretion of creatinine, sodium, potassium, protein and urea nitrogen. 


\begin{tabular}{|c|c|}
\hline $\mathrm{N}=18$ & $\begin{array}{c}\text { Mean } \\
\text { (range) }\end{array}$ \\
\hline Age (years) & $53 \pm 13$ \\
\hline Gender (male/female) & $9 / 9$ \\
\hline Height $(\mathrm{cm})$ & $174 \pm 8$ \\
\hline Weight (kg) & $81 \pm 10$ \\
\hline BMI $\left(\mathrm{kg} / \mathrm{m}^{2}\right)$ & $27 \pm 2.7$ \\
\hline Plasma creatinine $(\mu \mathrm{mol} / \mathrm{L})$ & $210 \pm 50$ \\
\hline $\mathrm{eGFR}\left(\mathrm{mL} / \mathrm{min} / 1.73 \mathrm{~m}^{2}\right)$ & $28 \pm 9$ \\
\hline Creatinine clearance $(\mathrm{mL} / \mathrm{min})$ & $48 \pm 18$ \\
\hline Plasma phosphorus (mmol/L) & $1.13 \pm 0.19$ \\
\hline Plasma ionized calcium $(\mathrm{mmol} / \mathrm{L})$ & $1.2 \pm 0.04$ \\
\hline FGF23 (pg/mL) & $145 \pm 123$ \\
\hline Parathyroid hormone (pmol/L) & $11.5 \pm 7$ \\
\hline Plasma sodium (mmol/L) & $140 \pm 2$ \\
\hline Plasma potassium $(\mathrm{mmol} / \mathrm{L})$ & $4.3 \pm 0.37$ \\
\hline 1,25-dihydroxyvitamin $\mathrm{D}(\mathrm{nmol} / \mathrm{L})$ & $77 \pm 35$ \\
\hline Plasma albumin $(\mathrm{g} / \mathrm{L})$ & $37 \pm 3$ \\
\hline \multicolumn{2}{|l|}{ Renal diagnosis, $n(\%)$} \\
\hline \multicolumn{2}{|l|}{ Autosomal dominant polycystic } \\
\hline kidney disease & $3(17)$ \\
\hline Vascular disease & $3(17)$ \\
\hline Chronic glomerulonephritis & $7(38)$ \\
\hline Diabetic nephropathy & $2(11)$ \\
\hline Unknown & $3(17)$ \\
\hline \multicolumn{2}{|l|}{ Race, $n(\%)$} \\
\hline Caucasian & $16(89)$ \\
\hline African & $2(11)$ \\
\hline \multicolumn{2}{|c|}{ Medication, constant 2 months before and during the study, $n$ (\%) } \\
\hline Antihypertensive medication & $17(94)$ \\
\hline Diuretics & $5(28)$ \\
\hline Uric acid-lowering therapy & $3(17)$ \\
\hline Proton pump inhibitor & $3(17)$ \\
\hline Vitamin D supplement & $2(11)$ \\
\hline
\end{tabular}

Values are expressed as mean \pm SD. BMI: body mass index.

Baseline data are presented as mean \pm SD or number (\%). Results are presented as mean \pm SD with corresponding P-values for comparisons between groups.

The primary endpoint was the evaluation of the difference in the change in 24-h urine phosphorus excretion from baseline to Day 7 between the NNRD and the habitual diet period of the study based on a mixed-effects model for repeated measures. Since no period effect, carry-over effect or interactions could be found, the model evaluating the effect was simplified to a paired $t$-test between the differences from baseline to Day 7 in the two arms of the study to better control for type 1 errors. P-values of 0.05 were considered statistically significant for all analyses.

The secondary outcomes were evaluated using the same models as the primary analysis. Analysis of Day 7 plasma biomarkers was based on a mixed-effects model for repeated measures.

The software employed for the analysis was $\mathrm{R}$ version 3.2.5 with the nlme package (R Project for Statistical Computing, Vienna, Austria).

\section{RESULTS}

\section{Demographic and clinical data}

A total of 20 patients were recruited and 2 patients dropped out, 1 because of acute uveitis and 1 because there was too much food to eat. Eighteen completed both diet periods and were analysed further. The time between the two diet periods was 7-21 days.

Demographic and clinical baseline data are summarized in Table 3.

\section{4-h urine phosphorus excretion and the 24-h urine fractional excretion of phosphorus}

The NNRD produced a reduction in the 24-h urine phosphorus excretion by $36 \%$ as compared with the habitual diet. The change in 24-h urine phosphorus excretion between the two diets was $313 \mathrm{mg} /$ day $(\mathrm{P}<0.001)$. The mean baseline phosphorus was $875 \pm 346 \mathrm{mg} /$ day and was decreased by $400 \pm 256 \mathrm{mg} /$ day in the NNRD and $87 \pm 266 \mathrm{mg} /$ day in the habitual diet (Figure 2A).

As compared with the habitual diet, the 24-h urine fractional excretion of phosphorus was reduced by the NNRD to $11 \%$ $(\mathrm{P}<0.001)$. The mean baseline phosphorus was $38 \pm 11 \%$ and was decreased by $12 \pm 11 \%$ in NNRD and $1 \pm 0.5 \%$ in the habitual diet (Figure 2B).

\section{Plasma intact FGF23, plasma phosphate and plasma potassium}

By testing for a change in FGF23 from baseline to Day 7 within the diet using a paired $t$-test, we found $\mathrm{P}$-values of 0.81 

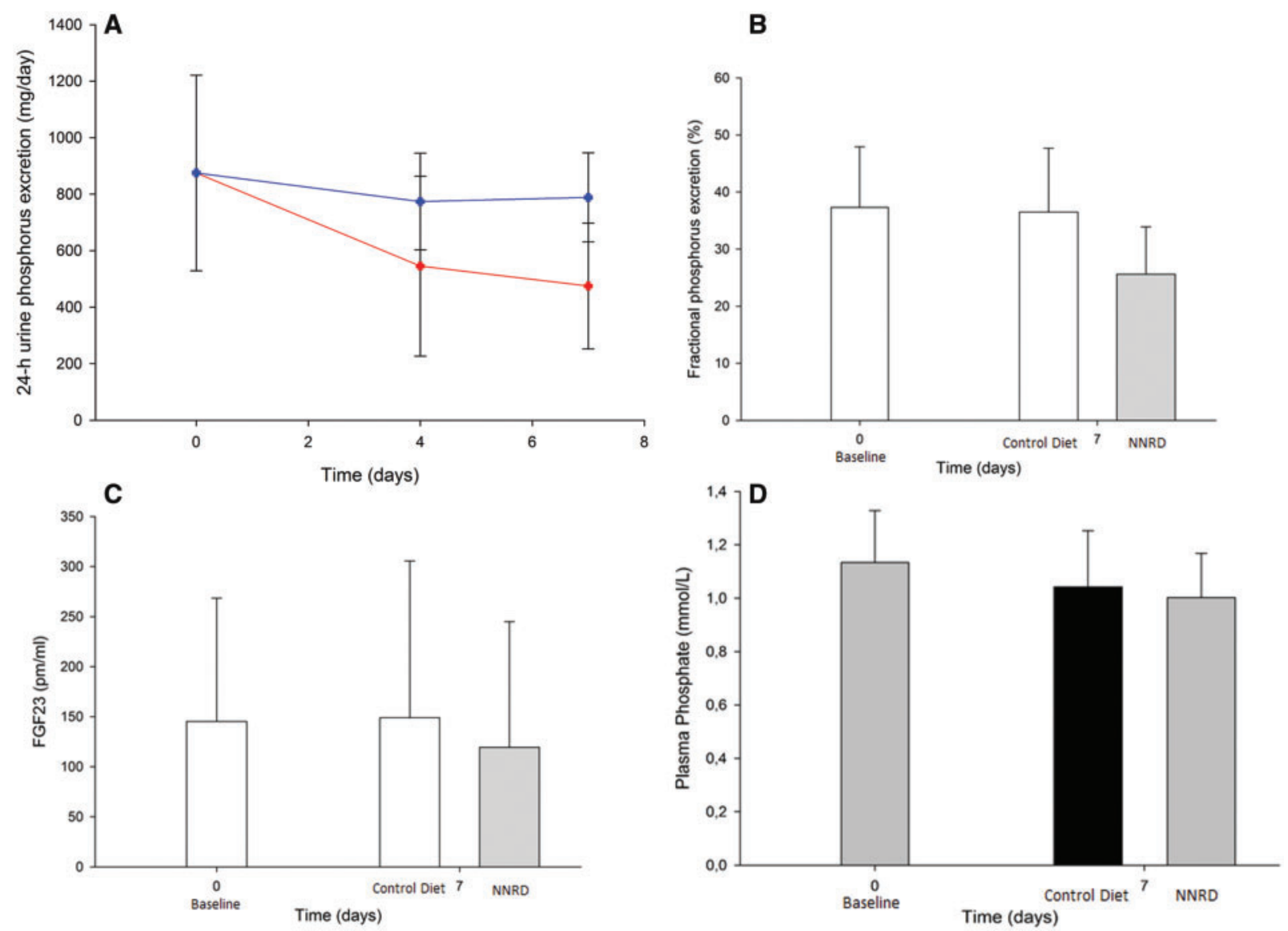

FIGURE 2: P-values for the differences in change across diets. Change in (A) 24-h urine phosphorus excretion (mg/day) $(\mathrm{P}<0.001)$ from baseline to Day 7 between NNRD and habitual diet. Data are presented as mean \pm SD, significance $P<0.05$. The NNRD can be presented as a dotted line and the habitual diet as a straight line. (B) Fractional phosphorus excretion $(\%)(\mathrm{P}<0.001)$ from baseline to Day 7 between the NNRD and habitual diet. Data are presented as mean $\pm \mathrm{SD}$, significance $\mathrm{P}<0.05$. (C) FGF23 (pm/mL) $(\mathrm{P}=0.03)$ from baseline to Day 7 between the NNRD and habitual diet. Data are presented as mean $\pm \mathrm{SD}$, significance $\mathrm{P}<0.05$. (D) Plasma phosphate $(\mathrm{mmol} / \mathrm{L})(\mathrm{P}=0.24)$ from baseline to Day 7 between the NNRD and habitual diet. Data are presented as mean $\pm \mathrm{SD}$, significance $\mathrm{P}<0.05$.

and 0.05 for the control diet and NNRD, respectively. The mean baseline plasma intact FGF23 was $145 \pm 123 \mathrm{pg} / \mathrm{mL}$ and decreased by $119 \pm 126 \mathrm{pg} / \mathrm{mL}$ in the NNRD and increased by $149 \pm 157 \mathrm{pg} / \mathrm{mL}$ in the habitual diet. The difference between the two dietary periods was $30 \mathrm{pg} / \mathrm{mL}(\mathrm{P}=0.03)$ (Figure 2C).

The difference in plasma phosphate between the NNRD and the habitual diet was unchanged $(\mathrm{P}=0.24)$. The mean baseline plasma phosphate was $1.13 \pm 0.19 \mathrm{mmol} / \mathrm{L}$ and decreased by $0.13 \pm 0.19 \mathrm{mmol} / \mathrm{L}$ in the NNRD and by $0.02 \pm 0.2 \mathrm{mmol} / \mathrm{L}$ in the habitual diet (Figure 2D).

There was no difference in plasma potassium between the NNRD and habitual diet $(P=0.106)$. The mean baseline plasma potassium was $4.26 \pm 0.39 \mathrm{mmol} / \mathrm{L}$ and changed by $0.11 \pm 0.14 \mathrm{mmol} / \mathrm{L}$ during the NNRD and by $0.03 \pm 0.1$ $\mathrm{mmol} / \mathrm{L}$ during the habitual diet.

GFR and associations between the 24-h urine phosphorus excretion, fractional excretion of phosphorous and FGF23

GFR was associated with 24-h urine phosphorus excretion, fractional excretion of phosphorous and FGF23. At Day 7, a linear model adjusted for diet was used to test the association and we found P-values of $0.02,0.006$ and 0.02 for an association between eGFR and $24 \mathrm{~h}$ urine phosphorus excretion, fractional excretion of phosphorous and FGF23, respectively.

24-h urine volume and excretion of sodium, potassium, creatinine, protein and urea nitrogen

The 24-h urine volume and excretion of protein, potassium and creatinine was without a difference between the two study periods $(\mathrm{P}=0.71, \mathrm{P}=0.46$ and $\mathrm{P}=0.43$, respectively). We found a significant decrease in 24 -h urine urea nitrogen excretion between baseline and Day 7 in the NNRD period [151 mmol/L $(\mathrm{P}<0.001)$; data not shown]. The 24 -h urine excretion of sodium increased significantly on the NNRD compared with the habitual diet $(\mathrm{P}=0.02)$.

\section{Weighed dietary food records for Days 1 and 4 during} the habitual diet week

The average estimated mean \pm SD intake of energy, phosphorus, protein and calcium according to the dietary records on Days 1 and 4 during the habitual diet week were $1776 \pm 717$ $\mathrm{kcal} /$ day, $\quad 1417 \pm 584 \mathrm{mg} /$ day, $0.9 \pm 0.35 \mathrm{~g} / \mathrm{kg} /$ day and $928 \pm 418 \mathrm{mg} /$ day, respectively. 

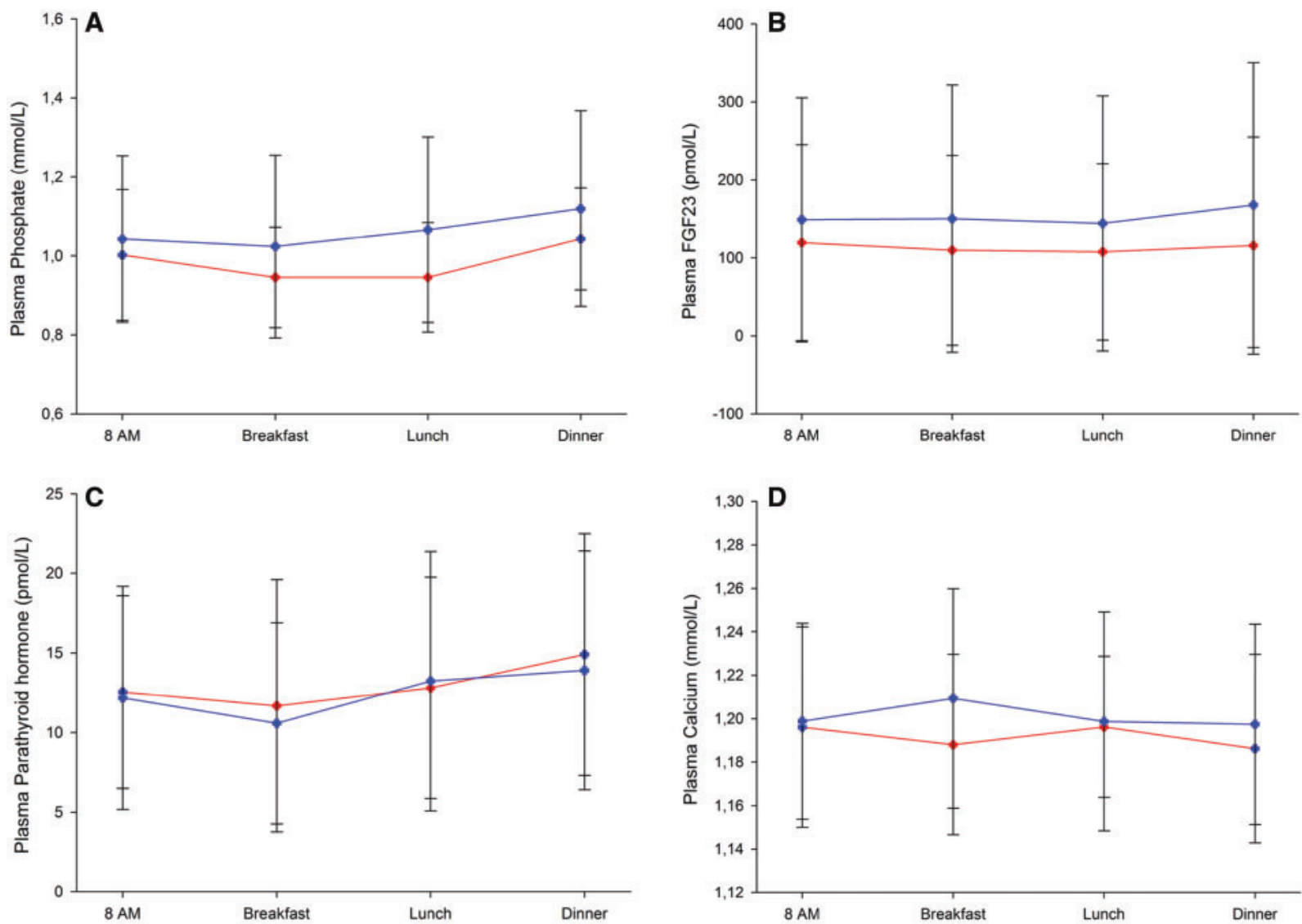

FIGURE 3: P-values are testing the difference across diets for all time points on Day 7. Dotted line indicates NNRD and straight line indicates control diet. Diurnal variation of $(\mathbf{A})$ plasma phosphate $(\mathrm{P}=0.45),(\mathbf{B})$ plasma intact FGF23 $(\mathrm{P}=0.45),(\mathrm{C})$ plasma $\mathrm{PTH}(\mathrm{P}=0.63),(\mathrm{D})$ plasma ionized calcium $(\mathrm{P}=0.08)$. Two diets with mean $\pm \mathrm{SD}$, fasting blood sample at 8.00 a.m., further samples collected 30 min after each meal (breakfast, lunch and dinner).

Variation of plasma phosphate, plasma intact FGF23, plasma PTH and plasma calcium during the day

During the inpatient stay on Day 7, we examined the circadian rhythm of plasma phosphate, plasma intact FGF23, plasma PTH and plasma ionized calcium by four measurements throughout the day with a morning fasting blood sample followed by a blood sample $30 \mathrm{~min}$ after each meal (Figure 3). Overall, we found no difference in plasma phosphate $(\mathrm{P}=0.45)$. The mean plasma phosphate was lowest at $13 \mathrm{pm} \mathrm{ol} / \mathrm{L}$ in the NNRD, whereas in the control diet it was lowest after breakfast. Plasma phosphate was highest after dinner (Figure 3A). Three patients had a plasma phosphate level above normal on Day 7 in the habitual diet, which normalized on Day 7 of the NNRD period (Figure 4). Plasma intact FGF23 was without a difference between the two diets $(\mathrm{P}=0.45)$ but showed less amplitude in the NNRD than in the control diet (Figure 3D). There was no difference in plasma ionized calcium and PTH on Day 7 between the two diets $(\mathrm{P}=0.08$ and $\mathrm{P}=0.63$, respectively) (Figure $3 \mathrm{C}$ and $\mathrm{D}$ ).

\section{Dietary compliance and satisfaction}

Of 18 participants, 16 stated that the NNRD tasted very good and 2 participants stated that it tasted good. Dietary compliance was kept at $100 \%$ and the participants felt satiated during the NNRD week.

\section{DISCUSSION}

This randomized controlled study shows convincingly that dietary reduction of phosphorus intake is both feasible and effective on a short-term basis; 18 CKD patients stayed for 1 week on the specially designed nutritiously balanced NNRD, which reduced their daily phosphorus intake by $\sim 650 \mathrm{mg} /$ day compared with their habitual diet. This dietary change had a rapid impact on important phosphorus indicators. Thus the 24$\mathrm{h}$ urine phosphorus excretion was reduced by almost $40 \%$, the urinary fractional phosphorus excretion by $29 \%$ and plasma intact FGF23 by $18 \%$ in the NNRD period. During the inpatient stay on Day 7, 3 of 18 patients were hyperphosphataemic on the control diet, and plasma phosphate was normalized on the NNRD in all three patients.

The NND has similarities to the two worldwide established diets preventing cardiovascular disease: the Mediterranean diet and the DASH diet [24, 27]; however, to be able to convert them into a CKD diet and accommodate a phosphorus intake in accordance with international 

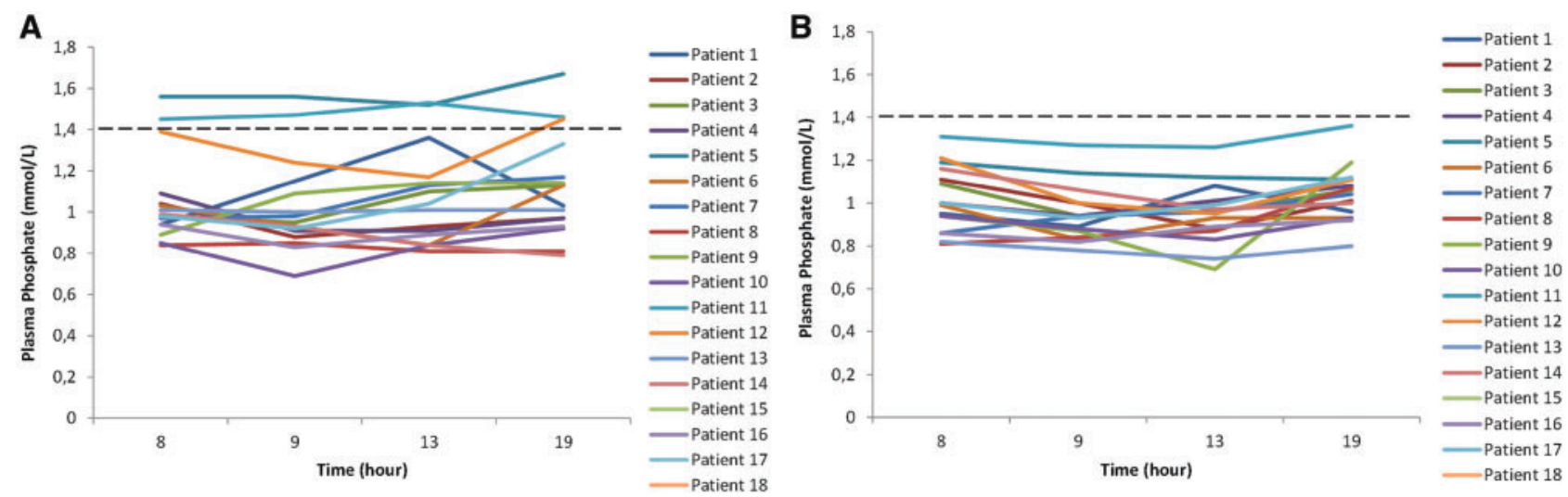

FIGURE 4: Spaghetti plot of plasma phosphate measurements on Day 7 for (A) the control diet and (B) the NNRD. Each line represents one patient. Cut-off for high plasma phosphate level is marked by a dotted horizontal line (normal range plasma phosphate $0.76-1.41 \mathrm{mmol} / \mathrm{L}$ ).

recommendations, one would have to reduce the phosphorus these diets.

A key nutrient difference between the habitual diet and NNRD was a higher intake of preserved food, convenience food, oatmeal, cold cuts, cheese, meat, dairy products and soft drinks during the habitual diet. Our results show that by replacing these nutrients with white bread for breakfast, salad for lunch and less animal-bound protein for dinner with vegetables, you will increase the intake of fibre by $12 \%$ and reduce the intake of phosphorus by $40 \%$.

Based on the dietary records, the average caloric intake during the habitual diet was $25 \%$ greater than during the NNRD.

The dietary satisfaction, compliance and satiation were high according to self-reporting questionnaires and evidenced by the SD in the 24-h urine phosphorus excretion, which was lower on Day 7 in the NNRD period compared with both baseline and the control Day 7. Several reasons known to increase adherence can explain this: the composition of the diet was kept simple and without too many restrictions and the food was handed out as packaged meals [13].

The significant reduced 24-h urine urea nitrogen excretion in the NNRD also confirms a lower intake of animal-based protein [28], whereas the daily protein intake was in accordance with international guidelines $(0.8 \mathrm{~g} / \mathrm{kg} /$ day) $[29,30]$. The higher 24-h urine sodium excretion during the NNRD period might be explained by lower dietary sodium intake during the habitual diet.

Other short-term studies focusing on phosphorus reduction in pre-dialysis CKD patients have been performed with a dietary intervention in combination with a phosphate binder, and the results are not very consistent. Isakova et al. [31] performed a study similar to ours comparing a $750 \mathrm{mg}$ phosphorus diet to a $1500 \mathrm{mg}$ phosphorus diet in combination with lanthanum carbonate or placebo with no reduction in plasma phosphate or FGF23. In contrast, Sigrist et al. [32] compared a high phosphorus diet (2000 mg) with a lower phosphorus diet (750 mg), also in combination with phosphate binder, and did find a significant FGF23 reduction within the lowdiet plus phosphate binder group but no change in plasma phosphate. This present study demonstrates that lowering dietary phosphorus intake to
$650 \mathrm{mg} /$ day and without pharmacological intervention you can obtain a positive result on FGF23 in moderate CKD patients.

We measured the intact FGF23, which is the biologically active portion of the protein orchestrating phosphaturia $[33,34]$, and it decreased during the NNRD period (Figure 2C). The greatest effect of the NNRD on plasma intact FGF23 was seen in patients with the highest levels (with a cut-off of $200 \mathrm{pg} / \mathrm{mL}$ plasma intact FGF23), which suggests that a low phosphorus diet may be more effective in patients with challenged phosphate homoeostasis.

Targeting phosphorus and FGF23 reduction by reducing meat intake, based on the theory that the intestinal absorption is important and that phosphorus uptake from animal products is much higher than from plant foods ( $80 \%$ versus $40 \%$ ), may be useful $[35,36]$. This was illustrated by Moe et al. [37] in a crossover study comparing a meat-based diet versus a vegetarian diet, showing a significant reduction in FGF23. The explanation being that phosphorus in plants is phytate bound and the human intestine does not secrete the enzyme phytase, which is necessary to degrade dietary phytate and release phosphorus $[38,39]$.

Our data do not allow us to conclude if the maximum effect of the NNRD on phosphorus homoeostasis is reached on intervention Day 7, as the 24-h urine phosphorus excretion seemed to decrease continuously during this diet (Figure 2A). This is interesting, as these kinetics might explain why other studies of dietary intervention studies with a duration $<5$ days did not show any change in 24-h urine phosphorus excretion [40, 41]. Long-term intervention studies are needed to explore this further.

Treatment with oral phosphate binders is generally recommended when overt hyperphosphataemia is present. Three of 18 participants presented with an elevated plasma phosphate level on Day 7 of the control diet and all of them normalized plasma phosphate when ingesting the NNRD (Figure 4), indicating that NNRD was especially beneficial for the patients with hyperphosphataemia.

The concept of treating with phosphate binders at the earlier stages of CKD before overt hyperphosphataemia is present has been tested in a study by Block et al. [42] with 
confusing results. In a placebo-controlled study, 106 CKD Stages 3-4 patients were randomized to placebo, Lanthanum, sevelamer carbonate or calcium acetate in 249 days. It was found that active therapy reduced 24 -h urinary phosphorus excretion but resulted in progression of vascular calcification, particularly among the patients who received calcium acetate.

\section{Limitations}

None of the participants were using phosphate binders and therefore were considered as a selected group in the lower range of plasma phosphate levels. During the habitual diet period, there were no blood tests taken on Days 1 and 4, which was due to reasons such as adherence and commitment to participate in this study. The participants did not have to spend time on grocery shopping or food preparation, which might have influenced the compliance positively.

In conclusion, the present study showed that by following the NNRD for 7 days, it is possible to improve parameters of phosphate homoeostasis in CKD patients. Whether this regionally tailored, easy-to-adapt diet applied long-term can promote beneficial outcomes in this patient population faced with so many risks and restrictions will have to be proven in a largescale, long-term study.

\section{AUTHORS’ CONTRIBUTIONS}

L.S., M.R., A.K. and A.A. designed the research. L.S., M.R., J.S. and A.K. conducted the research. All authors analysed and interpreted the data. L.S., A.A., A.K. and M.R. wrote the article and had primary responsibility for the final content. All authors contributed to the revision and final approval of the article.

\section{CONFLICT OF INTEREST STATEMENT}

M.R. reports personal fees from Amgen outside the submitted work. The authors declare no conflicts of interest. This article has not been published previously in whole or part.

(See related article by Scialla and Lin. Revamping the 'renal' diet: using foods to control phosphorus physiology. Nephrol Dial Transplant 2019; 34: 1619-1622)

\section{REFERENCES}

1. Dhingra R, Gona P, Benjamin EJ et al. Relations of serum phosphorus levels to echocardiographic left ventricular mass and incidence of heart failure in the community. Eur J Heart Fail 2010; 12: 812-818

2. Kestenbaum B, Sampson JN, Rudser KD et al. Serum phosphate levels and mortality risk among people with chronic kidney disease. J Am Soc Nephrol 2005; 16: 520-528

3. Abramowitz M, Muntner P, Coco M et al. Serum alkaline phosphatase and phosphate and risk of mortality and hospitalization. Clin J Am Soc Nephrol 2010; 5: 1064-1071

4. Tonelli M, Sacks F, Pfeffer M et al. Relation between serum phosphate level and cardiovascular event rate in people with coronary disease. Circulation 2005; 112: 2627-2633

5. Gutiérrez OM, Mannstadt M, Isakova T et al. Fibroblast growth factor 23 and mortality among patients undergoing hemodialysis. N Engl J Med 2008; 359: 584-592
6. Seiler S, Reichart B, Roth D et al. FGF-23 and future cardiovascular events in patients with chronic kidney disease before initiation of dialysis treatment. Nephrol Dial Transplant 2010; 25: 3983-3989

7. Isakova T, Ix JH, Sprague SM et al. Rationale and approaches to phosphate and fibroblast growth factor 23 reduction in CKD. J Am Soc Nephrol 2015; 26: $2328-2339$

8. Oliveira RB, Cancela ALE, Graciolli FG et al. Early control of PTH and FGF23 in normophosphatemic CKD patients: a new target in CKD-MBD therapy? Clin J Am Soc Nephrol 2010; 5: 286-291.

9. Yilmaz MI, Sonmez A, Saglam M et al. Comparison of calcium acetate and sevelamer on vascular function and fibroblast growth factor 23 in CKD patients: a randomized clinical trial. Am J Kidney Dis 2012; 59: 177-185

10. Hill KM, Martin BR, Wastney ME et al. Oral calcium carbonate affects calcium but not phosphorus balance in stage 3-4 chronic kidney disease. Kidney Int 2013; 83: 959-966

11. Spatz C, Roe K, Lehman E et al. Effect of a non-calcium-based phosphate binder on fibroblast growth factor 23 in chronic kidney disease. Nephron Clin Pract 2013; 123: 61-66

12. Liabeuf S, Ryckelynck JP, El Esper $\mathrm{N}$ et al. Randomized clinical trial of sevelamer carbonate on serum klotho and fibroblast growth factor 23 in CKD. Clin J Am Soc Nephrol 2017; 12: 1930-1940

13. Beto JA, Schury KA, Bansal VK. Strategies to promote adherence to nutritional advice in patients with chronic kidney disease: a narrative review and commentary. Int J Nephrol Renov Dis 2016; 9: 21-33

14. Moshfegh A, Goldman J, Ahuja JK, Rhodes D, LaComb R. What we eat in America. NHANES 2005-2006. In: Usual nutrient intakes from food and water compared to 1997 Dietary Reference Intake for vitamin D, calcium, phosphorus and magnesium. USDA/Agricultural ResearchService; 2009, https://www.ars.usda.gov/research/publications/publication/?seqNo115= 243279.

15. Salomo L, Kamper A-L, Poulsen GM et al. Habitual dietary phosphorus intake and urinary excretion in chronic kidney disease patients: a 3-day observational study. Eur J Clin Nutr 2017; 71: 798-800

16. Trichopoulou A, Costacou T, Bamia C et al. Adherence to a Mediterranean diet and survival in a Greek population. $N$ Engl J Med 2003; 348: 2599-2608

17. Appel LJ, Moore TJ, Obarzanek E et al. A clinical trial of the effects of dietary patterns on blood pressure. N Engl J Med 1997; 336: 1117-1124

18. Appel LJ, Brands MW, Daniels SR et al. Dietary approaches to prevent and treat hypertension: a scientific statement from the American Heart Association. Hypertension 2006; 47: 296-308

19. Chrysohoou C, Panagiotakos DB, Pitsavos C et al. Adherence to the Mediterranean diet is associated with renal function among healthy adults: the ATTICA study. J Ren Nutr 2010; 20: 176-184

20. Rebholz CM, Crews DC, Grams ME et al. DASH (Dietary Approaches to Stop Hypertension) diet and risk of subsequent kidney disease. Am J Kidney Dis 2016; 68: 853-861

21. Chauveau P, Aparicio M, Bellizzi V et al. Mediterranean diet as the diet of choice for patients with chronic kidney disease. Nephrol Dial Transplant 2018; 33: 725-735

22. Poulsen SK, Due A, Jordy AB et al. Health effect of the New Nordic Diet in adults with increased waist circumference: a 6-mo randomized controlled trial. Am J Clin Nutr 2014; 99: 35-45

23. Salomo L, Poulsen SK, Rix M et al. The New Nordic Diet: phosphorus content and absorption. Eur J Nutr 2016; 55: 991-996

24. Mithril C, Dragsted LO, Meyer C et al. Dietary composition and nutrient content of the New Nordic Diet. Public Health Nutr 2013; 16: 777-785

25. Renzella J, Townsend N, Jewell J et al. What National and Subnational Interventions and Policies Based on Mediterranean and Nordic Diets Are Recommended or Implemented in the WHO European Region, and Is There Evidence of Effectiveness in Reducing Noncommunicable Diseases? Health Evidence Network Synthesis Report. Copenhagen: WHO Regional Office for Europe, 2018

26. Murakami K, Sasaki S, Takahashi Y et al. Sensitivity and specificity of published strategies using urinary creatinine to identify incomplete 24 -h urine collection. Nutrition 2008; 24: 16-22

27. Gallieni M, Cupisti A. DASH and Mediterranean diets as nutritional interventions for CKD patients. Am J Kidney Dis 2016; 68: 82830 
28. Kalantar-Zadeh K, Moore LW, Tortorici AR et al. North American experience with Low protein diet for non-dialysis-dependent chronic kidney disease. BMC Nephrol 2016; 17: 90

29. KDIGO clinical practice guideline for the evaluation and management of chronic kidney disease. Kidney Int Suppl 2012; 3: 1-150

30. Kalantar-Zadeh K, Fouque D. Nutritional management of chronic kidney disease. N Engl J Med 2017; 377: 1765-1776

31. Isakova T, Gutiérrez OM, Smith $\mathrm{K}$ et al. Pilot study of dietary phosphorus restriction and phosphorus binders to target fibroblast growth factor 23 in patients with chronic kidney disease. Nephrol Dial Transplant 2011; 26: 584-591

32. Sigrist M, Tang M, Beaulieu M et al. Responsiveness of FGF-23 and mineral metabolism to altered dietary phosphate intake in chronic kidney disease (CKD): results of a randomized trial. Nephrol Dial Transplant 2013; 28: 161-169

33. Shimada T, Muto T, Urakawa I et al. Mutant FGF-23 responsible for autosomal dominant hypophosphatemic rickets is resistant to proteolytic cleavage and causes hypophosphatemia in vivo. Endocrinology 2002; 143: 3179-3182

34. Ito N, Fukumoto S, Takeuchi Y et al. Comparison of two assays for fibroblast growth factor (FGF)-23. J Bone Miner Metab 2005; 23: 435-440

35. Karp HJ, Vaihia KP, Kärkkäinen MUM et al. Acute effects of different phosphorus sources on calcium and bone metabolism in young women: a whole-foods approach. Calcif Tissue Int 2007; 80: 251-258
36. St-Jules DE, Jagannathan R, Gutekunst L et al. Examining the proportion of dietary phosphorus from plants, animals, and food additives excreted in urine. J Ren Nutr 2017; 27: 78-83

37. Moe SM, Zidehsarai MP, Chambers MA et al. Vegetarian compared with meat dietary protein source and phosphorus homeostasis in chronic kidney disease. Clin J Am Soc Nephrol 2011; 6: 257-264

38. Iqbal TH, Lewis KO, Cooper BT. Phytase activity in the human and rat small intestine. Gut 1994; 35: 1233-1236

39. Schlemmer U, Frølich W, Prieto RM et al. Phytate in foods and significance for humans: food sources, intake, processing, bioavailability, protective role and analysis. Mol Nutr Food Res 2009; 53(Suppl 2): S330-S375

40. Ix JH, Anderson CAM, Smits G et al. Effect of dietary phosphate intake on the circadian rhythm of serum phosphate concentrations in chronic kidney disease: a crossover study. Am J Clin Nutr 2014; 100: 1392-1397

41. Vervloet MG, van Ittersum FJ, Büttler RM et al. Effects of dietary phosphate and calcium intake on fibroblast growth factor-23. Clin J Am Soc Nephrol 2011; 6: 383-389

42. Block GA, Wheeler DC, Persky MS et al. Effects of phosphate binders in moderate CKD. J Am Soc Nephrol 2012; 23: 1407-1415

Received: 12.6.2018; Editorial decision: 29.10.2018

\title{
Proteinuria and cholesterol reduction are independently associated with less renal function decline in statin-treated patients; a post hoc analysis of the PLANET trials
}

\author{
Nienke M.A. Idzerda ${ }^{1}$, Michelle J. Pena ${ }^{1}$, Hans-Henrik Parving ${ }^{2}$, Dick de Zeeuw ${ }^{1}$ and Hiddo J.L. Heerspink ${ }^{1}$ \\ ${ }^{1}$ Department of Clinical Pharmacy and Pharmacology, University Medical Center Groningen, University of Groningen, Groningen, The \\ Netherlands and ${ }^{2}$ Department of Medical Endocrinology, Rigshospitalet, University of Copenhagen, Copenhagen, Denmark
}

Correspondence and offprint requests to: Hiddo J.L. Heerspink; E-mail: h.j.lambers.heerspink@umcg.nl

\section{ABSTRACT}

Background. Statins have shown multiple effects on different renal risk factors such as lowering of total cholesterol (TC) and lowering of urine protein:creatinine ratio $\left(\mathrm{U}_{\mathrm{PCR}}\right)$. We assessed whether these effects of statins vary between individuals, the extent of discordance of treatment effects on both TC and $\mathrm{U}_{\mathrm{PCR}}$ within an individual, and the association of responses in TC and $\mathrm{U}_{\mathrm{PCR}}$ with estimated glomerular filtration rate (eGFR) decline.

Methods. The PLANET I and II (Renal effects of Rosuvastatin and Atorvastatin in Patients Who Have Progressive Renal Disease) trials examined effects of atorvastatin and rosuvastatin on proteinuria and renal function in patients with proteinuria. We post hoc analysed 471 therapy-adherent proteinuric patients from the two trials and assessed the individual variability in $\mathrm{U}_{\mathrm{PCR}}$ and $\mathrm{TC}$ response from 0 to 14 weeks and whether these responses were predictive of eGFR decline during the subsequent 9 months of follow-up.

Results. $\mathrm{U}_{\mathrm{PCR}}$ and TC response varied between individuals: mean $\mathrm{U}_{\mathrm{PCR}}$ response was $-1.3 \%$ (5th-95th percentile -59.9 to 141.8 ) and mean TC response was $-93.9 \mathrm{mg} / \mathrm{dL}(-169.1$ to -26.9$)$. Out of 471 patients, 123 (26.1\%) showed a response in $\mathrm{U}_{\mathrm{PCR}}$ but not in $\mathrm{TC}$, and $96(20.4 \%)$ showed a response in TC but not in $\mathrm{U}_{\mathrm{PCR}}$. eGFR $\left(\mathrm{mL} / \mathrm{min} / 1.73 \mathrm{~m}^{2}\right)$ did not decrease significantly from baseline in both $\mathrm{U}_{\mathrm{PCR}}$ responders $[0.4 ; 95 \%$ confidence interval $(\mathrm{CI})$ -1.6 to $0.9 ; \mathrm{P}=0.54$ ] and $\mathrm{TC}$ responders $(0.3 ; 95 \% \mathrm{CI}-1.8$ to $1.1 ; \mathrm{P}=0.64)$, whereas $\mathrm{U}_{\mathrm{PCR}}$ and TC non-responders showed a significant decline in eGFR from baseline $(1.8 ; 95 \%$ CI $0.6-3.0$; $\mathrm{P}=0.004$ and $1.7 ; 95 \% \mathrm{CI} 0.5-2.9 ; \mathrm{P}=0.007$, respectively). A lack of response in both parameters resulted in the fastest rate of eGFR decline (2.1; 95\% CI $0.5-3.7 ; \mathrm{P}=0.01$ ). These findings were not different for rosuvastatin or atorvastatin.

(C) The Author(s) 2018. Published by Oxford University Press on behalf of ERA-EDTA.

This is an Open Access article distributed under the terms of the Creative Commons Attribution Non-Commercial License (http://creativecommons.org/licenses/ by-nc/4.0/), which permits non-commercial re-use, distribution, and reproduction in any medium, provided the original work is properly cited. For commercial re-use, please contact journals.permissions@oup.com 